13

\title{
Влияние поверхностно-активных связей углеродных структур на разрядно-зарядные процессы источника тока
}

\author{
(C) А.П. Кузьменко, Е.А. Гречушников, В.А. Харсеев
}

Юго-Западный государственный университет, 305040 Курск, Россия

e-mail: apk3527@mail.ru

(Поступило в Редакцию 27 декабря 2016 г.)

\begin{abstract}
Проведено изучение влияния на разрядно-зарядные процессы источника тока поверхностно-активных связей углеродных структур, используемых в виде добавок в состав отрицательного электродного материала. Предложен механизм, основанный на выводах, вытекающих из молекулярно-кинетической теории КосселяСтранского, объясняющий рост кристаллов $3 \mathrm{PbOPbSO}_{4} \mathrm{H}_{2} \mathrm{O}$ при введении углеродных материалов. Установлено, что присутствие углеродных добавок в составе отрицательного электродного материала стартерных свинцово-кислотных батарей повышает емкость 20-h режима разряда - до $5 \%$, длительность разряда током холодной прокрутки до конечного напряжения $6 \mathrm{~V}$ при отрицательных температурах $-18^{\circ} \mathrm{C}$ на $3-4.5 \%$ и при $-30^{\circ} \mathrm{C}$ на $9-13 \%$.
\end{abstract}

DOI: 10.21883/JTF.2017.09.44925.2151

Углеродные добавки в различных модификациях (аморфные или кристаллические [1-4], углеродные нанотрубки $[5,6]$ и др.) в составе отрицательных электродных материалов (ОЭМ) за счет структурных особенностей и наличия поверхностно-функциональных групп повышают эксплуатационные характеристики свинцовокислотных аккумуляторов (СКА). В частности, на рост и развитость поверхности базовых для СКА кристаллов сульфатов свинца существенное влияние оказывают адсорбционные процессы с участием солей и ингибитора, значение $\mathrm{pH}$, рельеф поверхности.

Натоящая работа посвящена анализу структурных и фазовых изменений в ОЭМ в зависимости от количества аморфной углеродной добавки (УД) в виде широко используемого углерода марки П803, получаемого термоокислительным разложением жидких углеводородов, характеризуемого высокой развитостью поверхности (удельная условная поверхность $14-18 \mathrm{~m}^{2} / \mathrm{g}$ ), и установлению механизма влияния УД на электрические характеристики СКА.

Испытываемые ОЭМ готовились с использованием высокоокисленного свинцового порошка (77-79\% $\mathrm{PbO}$ ) и водного раствора $\mathrm{H}_{2} \mathrm{SO}_{4}$ (плотностью $1.4 \mathrm{~g} / \mathrm{cm}^{3}$ ), а также УД в виде технического углерода, $\mathrm{BaSO}_{4}$ и органического расширителя на основе лигносульфоната.

На всех стадиях приготовления ОЭМ и с разным содержанием УД проводился рентгенофазовый анализ

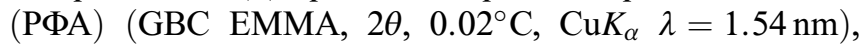
изучались морфология поверхности ОЭМ на сканирующем растровом электронном микроскопе (CЭМ) (JEOL JSM-6610LV $3 \mathrm{~nm}, 30 \mathrm{kV}$ ) и колебательные возбуждения в диапазоне $500-1800 \mathrm{~cm}^{-1}$ на ИК Фурье-спектрометре (Nicolet iS50, $0.125 \mathrm{~cm}^{-1}$ с HПВО).

Основными фазовыми составляющими ОЭМ были трехосновный сульфат свинца (3BS) $-3 \mathrm{PbOPbSO}_{4} \mathrm{H}_{2} \mathrm{O}$ и оксид свинца - $\alpha-\mathrm{PbO}$, что согласуется с данны- ми [1], содержание которых не изменялось для всех исследованных составов с содержанием УД $(0.2,0.4$, 0.6, 0.8 и 1.0\%). Морфология поверхности ОЭМ проиллюстрирована СЭМ-изображениями (рис. 1), на основании которых были выявлены изменения размеров кристаллических структур (рис. 2). Характерные размеры призматической слоистой структуры $3 \mathrm{BS}$ как по длине $L$, так и по поперечному размеру $D$ на микронном уровне изменялись явно нелинейно в зависимости от содержания УД $L(C)$ и $D(C)$. Так, при содержании УД от 0.2 до $0.6 \% L$ уменьшалась от 3 до $1.5 \mu \mathrm{m}$, тогда как поперечные размеры этих же кристаллов оставались практически неизменными и лежали в пределах $1 \mu \mathrm{m}$. Разность $L(C)-D(C)$, так же как и величина аспектного отношения $L / D$ при содержании УД, увеличивались, достигая насыщения при $0.8 \%$. Фактически все изменения размеров структуры 3BS в ОЭМ лежали в микроразмерной области.

Анализ ИК Фурье-спектров выявил различия в химической структуре исходной УД после щелочной или кислотной обработки в виде возбуждения поверхностных функциональных групп кислотной природы в диапазоне $800-1580 \mathrm{~cm}^{-1}$.

В ИК Фурье-спектрах ОЭМ после дозревания помимо линий поглощения, характерных для 3BS (596, 607, 960, $\left.1034,1087,1129 \mathrm{~cm}^{-1}\right)$, возникала широкая полоса с максимумом на $1405 \mathrm{~cm}^{-1}$, отвечающая валентным антисимметричным колебаниям $v_{3}$ группы $\mathrm{CO}_{3}^{2-}$ гидроцеррусита $-2 \mathrm{~Pb}\left(\mathrm{CO}_{3}\right) \mathrm{Pb}(\mathrm{OH})_{2}$ (рис. 3), содержание которого зависело от концентрации УД (вставка к рис. 3) [1,6], что также подтверждено данными РФА на характерной линии $2 \theta=24.7^{\circ}$. Наибольшая степень кристалличности 3BS достигалась при содержании УД $0.2 \%$.

Обнаруженные структурно-фазовые изменения ОЭМ могут быть вызваны наличием на поверхности УД поверхностно-активных связей, которые даже в незначи- 

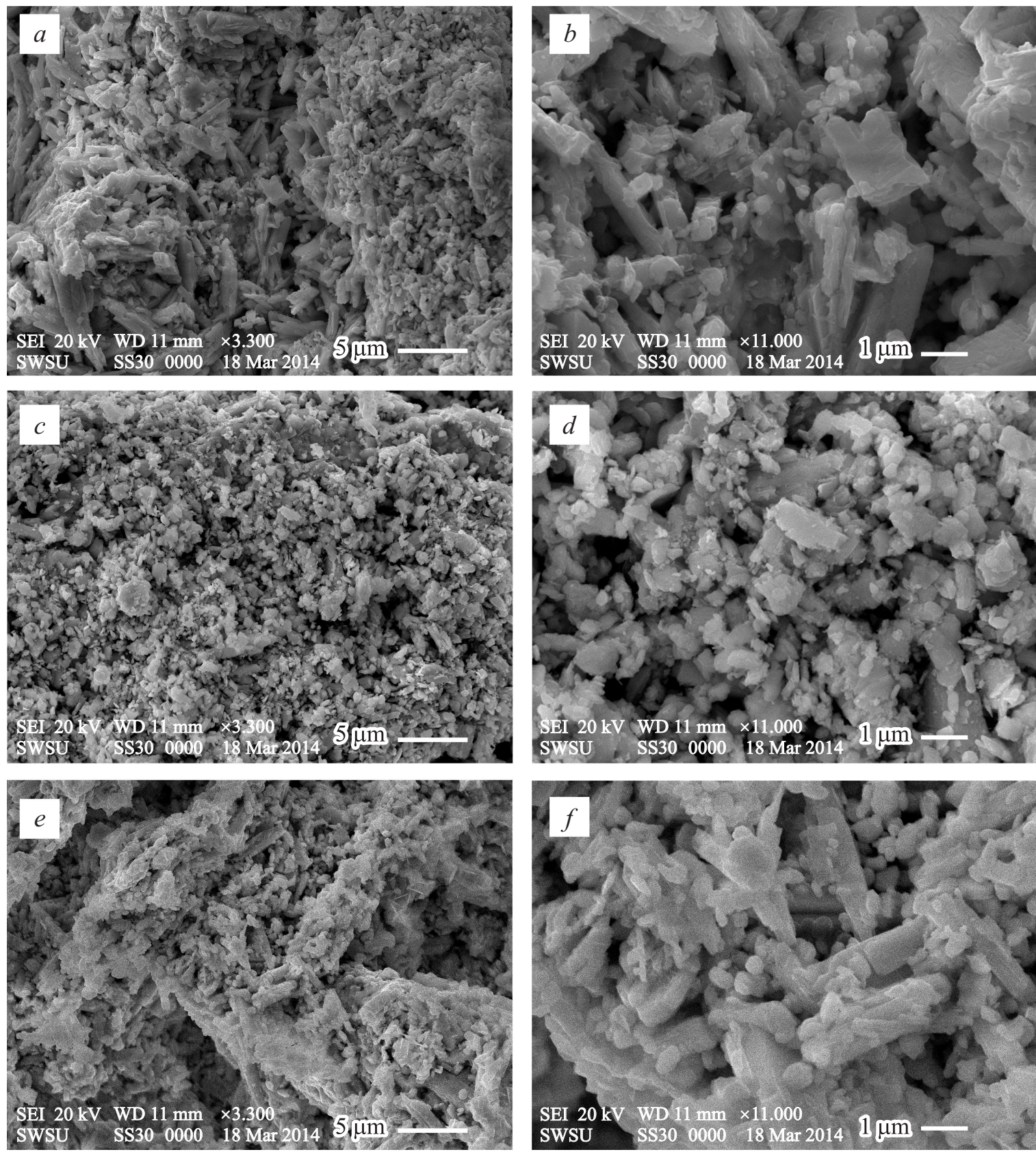

Рис. 1. Структура ОЭМ с различным содержанием углерода (\%): $a, b-0.2 ; c, d-0.6 ; e, f-1.0 \%$.

тельных количествах (всего в несколько ррm) способны оказывать ингибирующее воздействие на рост кристаллов [5], блокируя рост кристаллов как в ОЭМ, так и в положительных электродных материалах [4].

Анализ СЭМ изображений (рис. 1) схематично может быть представлен в виде следующих сценариев кристаллизации 3BS на разных стадиях подготовки и дозревания ОЭМ как без, так и с УД (вставка к рис. 2, $a-c)$, построенных с учетом выводов молекулярно-кинетической теории роста Косселя-Странского [8]. На рис. 2, продемонстрировано энергетически выгодное послойное наращивание поверхностей с низкой развитостью кристаллов 3BS без УД. Поверхностно-активные УД с повышенной способностью к адсорбции на поверхностях кристаллов 3BS препятствовало их росту и делало энергетически выгодным рост, по крайней мере, на 2 гранях, как это показано на рис. 2, $b$ - положение 2 . По мере заполнения этого канала роста кристаллов 3BS энергетически выгодным становилось также образование нового слоя на их отдельных гранях (рис. 2, $b-$ положение 3). Повышение адсорбции частиц УД на растущих гранях кристалла $3 \mathrm{BS}$ сопровождалось разупорядочением и повышением шероховатости (рис. 2,c). Отметим, что рост содержания частиц УД способен как замедлять рост кристаллов 3BS, так и препятствовать ему [1]. Из сопоставления СЭМ изображений ОЭМ 

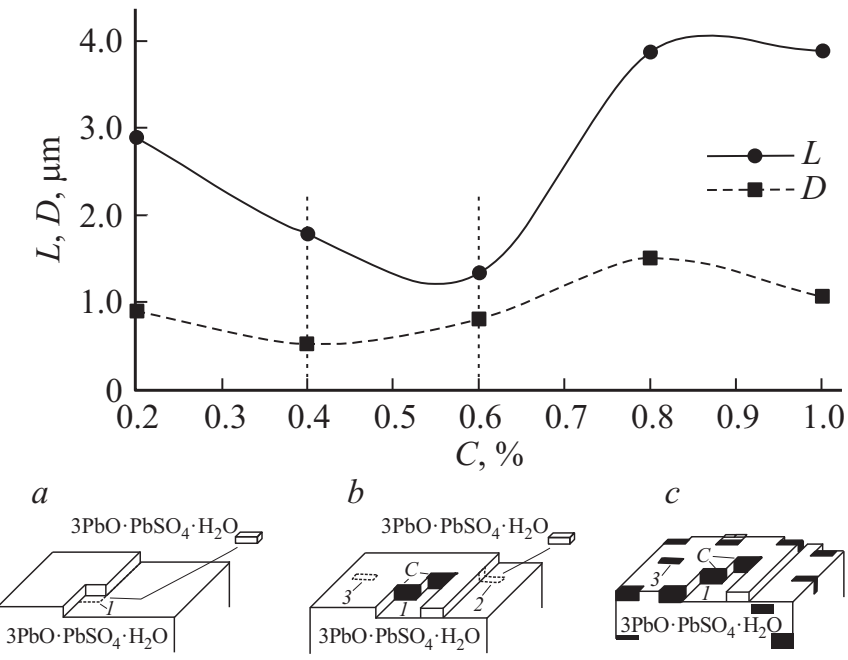

Рис. 2. Зависимость характерных размеров $L$ и $D$ кристаллов 3BS от содержания УД. На вставке схематичное представление роста кристалла 3BS при приготовлении и дозревании ОЭМ: без участия $(a)$ и с участием УД $(b, c)$.

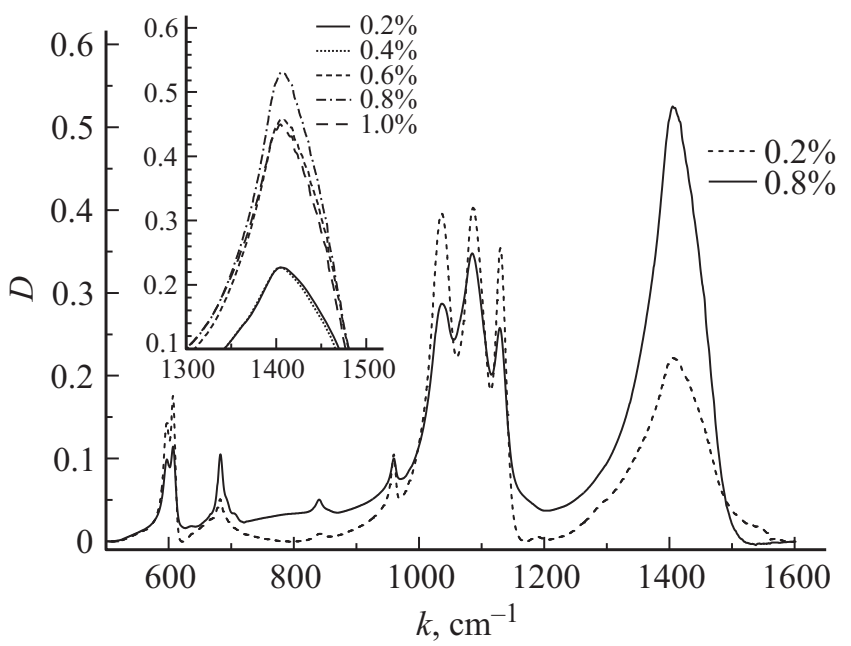

Рис. 3. ИК спектры сухого ЭМ после дозревания с разным содержанием УД. На вставке представлен фрагмент ИК спектра в области, соответствующей поглощению на кристаллах гидроцеррусита при всех исследованных содержаниях УД.

(рис. 1) можно видеть, что наиболее заметные изменения в строении кристаллов $3 \mathrm{BS}$ возникали при введении УД от 0.6 до $1.0 \%$.

Отмеченные особенности роста кристаллической структуры 3BS в ОЭМ после его дозревания были подтверждены данными электрических испытаний СКА. Номинальная емкость образцов СКА по результатам испытаний (при токе разряда $3 \mathrm{~A}$ ) линейно нарастала (до 5\%) при росте концентрации УД от 0.2 до $0.8 \%$, достигая насыщения при $1.0 \%$. Положительное влияние углеродных включений было подтверждено также испытаниями СКА разрядом тока холодной прокрутки при отрицательных температурах: 600 А при $-18^{\circ} \mathrm{C}$ и $400 \mathrm{~A}$ при $-30^{\circ} \mathrm{C}$ с ростом продолжительности разряда на $3-4.5$ и на $9-13 \%$ соответственно. Следует отметить явно положительную динамику роста продолжительности разряда с понижением температуры.

Такие изменения номинальной емкости и продолжительности разряда, а также рост их значений, впервые выявленный в [6], при добавлении углеродных наноструктур могут быть объяснены с учетом классического уравнения Нернста применительно к СКА. Величина напряжения холостого хода аккумулятора приближается к электродвижущей силе только при условиях уменьшения потерь на внутреннем сопротивлении $(J R)$ и на поляризацию $\left(\varepsilon_{\Sigma}\right)[1]$ :

$$
U=E-\varepsilon_{\Sigma}-J R
$$

где $U, E$ и $J-$ напряжение, ЭДС и ток, а

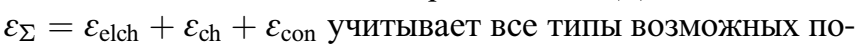
ляризаций (электрохимическую $-\varepsilon_{\text {elch }}$, химическую $\varepsilon_{\text {ch }}$, концентрационную $\left.-\varepsilon_{\text {con }}\right)$. Очевидно, значение $J$ с учетом роста площади поверхности активной электродной массы, вызванного добавлением либо УД, либо углеродных наноструктур, сопротивление которых $(R=\rho l / S)$ возрастает, будет уменьшаться. Возникающее в этих условиях уменьшение тока приведет к дополнительному снижению поляризации и приближению напряжения СКА к ЭДС согласно (1).

Таким образом, введение в качестве добавки технического углерода в состав отрицательного электродного материала свинцово-кислотного аккумулятора повышало на 5\% емкость 20-часового режима разряда, увеличивало длительность разряда батареи током холодной прокрутки до конечного напряжения $6 \mathrm{~V}$ при отрицательных температурах $-18^{\circ} \mathrm{C}$ на $3-4.5 \%$ и при $-30^{\circ} \mathrm{C}$ на $9-13 \%$.

Работа выполнена при финансовой поддержке Министерства образования и науки России в рамках соглашения № 14.577.21.0181 (Уникальный идентификатор соглашения RFMEFI57715X0181) и базовой части государственного задания (проект № 39.13).

\section{Список литературы}

[1] Lead-acid batteries: Science and technology. A handbook of lead acid battery technology and its influence on the product. First edition s.l. / D. Pavlov. Elsevier science, 2011. 656 p.

[2] Pavlov D., Nikolov P. // J. Power Sources. 2013. Vol. 242. P. 380.

[3] Xiang J., Ding P., Zhang H., Wu X., Chen J., Yang Y. // J. Power Sources. 2013. Vol. 241. P. 150.

[4] Kuzmenko A.P., Grechushnikov E.A., Kharseev V.A., Dobromyslov M.B. // J. Nano- and Electron. Phys. 2014. Vol. 6. N 3. P. 03025-1.

[5] Sugumaran N., Everill P., Swogger S.W., Dubey D.P. // J. Power Sources. 2015. Vol. 279. P. 281.

[6] Кузьменко А.П., Гречушников Е.А., Харсеев В.А. // Известия Юго-Западного государственного университета. Сер. техника и технологии. 2015. № 1(14). С. 73. 